\title{
Carnets
}

Revue électronique d'études françaises de l'APEF

Première Série - 3| 2011

$L^{\prime}($ In)vraisemblable

\section{De l'histoire naturelle aux œuvres contemporaines}

\section{Marise Laget}

\section{OpenEdition}

Journals

Édition électronique

URL : http://journals.openedition.org/carnets/6240

DOI : $10.4000 /$ carnets.6240

ISSN : 1646-7698

Éditeur

APEF

Édition imprimée

Date de publication : 2 janvier 2011

Pagination : 215-228

\section{Référence électronique}

Marise Laget, «De I'histoire naturelle aux œuvres contemporaines », Carnets [En ligne], Première Série 3 | 2011, mis en ligne le 18 juin 2018, consulté le 24 septembre 2020. URL : http:// journals.openedition.org/carnets/6240; DOI : https://doi.org/10.4000/carnets.6240

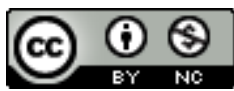

Carnets est mis à disposition selon les termes de la licence Creative Commons - Atribution - Pas d'utilisation commerciale 4.0 International. 


\section{DE L'HISTOIRE NATURELLE AUX FUVRES CONTEMPORAINES}

MARISE LAGET

Dans le cadre de la Fête de la Science, l'Apreca, Atelier Public de Recherche et Création Artistique, a lancé un appel à projets en partenariat avec le Musée Requien, Musée d'Histoire Naturelle d'Avignon. J'ai fait partie des quatorze artistes plasticiens sélectionnés pour réaliser une création sur le thème "De l'histoire naturelle aux œuvres contemporaines".

Dans vingt-trois des vitrines du Musée, parmi les objets qu'elles contiennent et présentent, j'ai placé une photo, sélectionnée dans mes archives ou prise pour le projet. Cette photo peut passer pour appartenant aux collections. Elle est assortie d'un cartel dont le texte reprend le style de ceux du Musée, sur un mode décalé. 


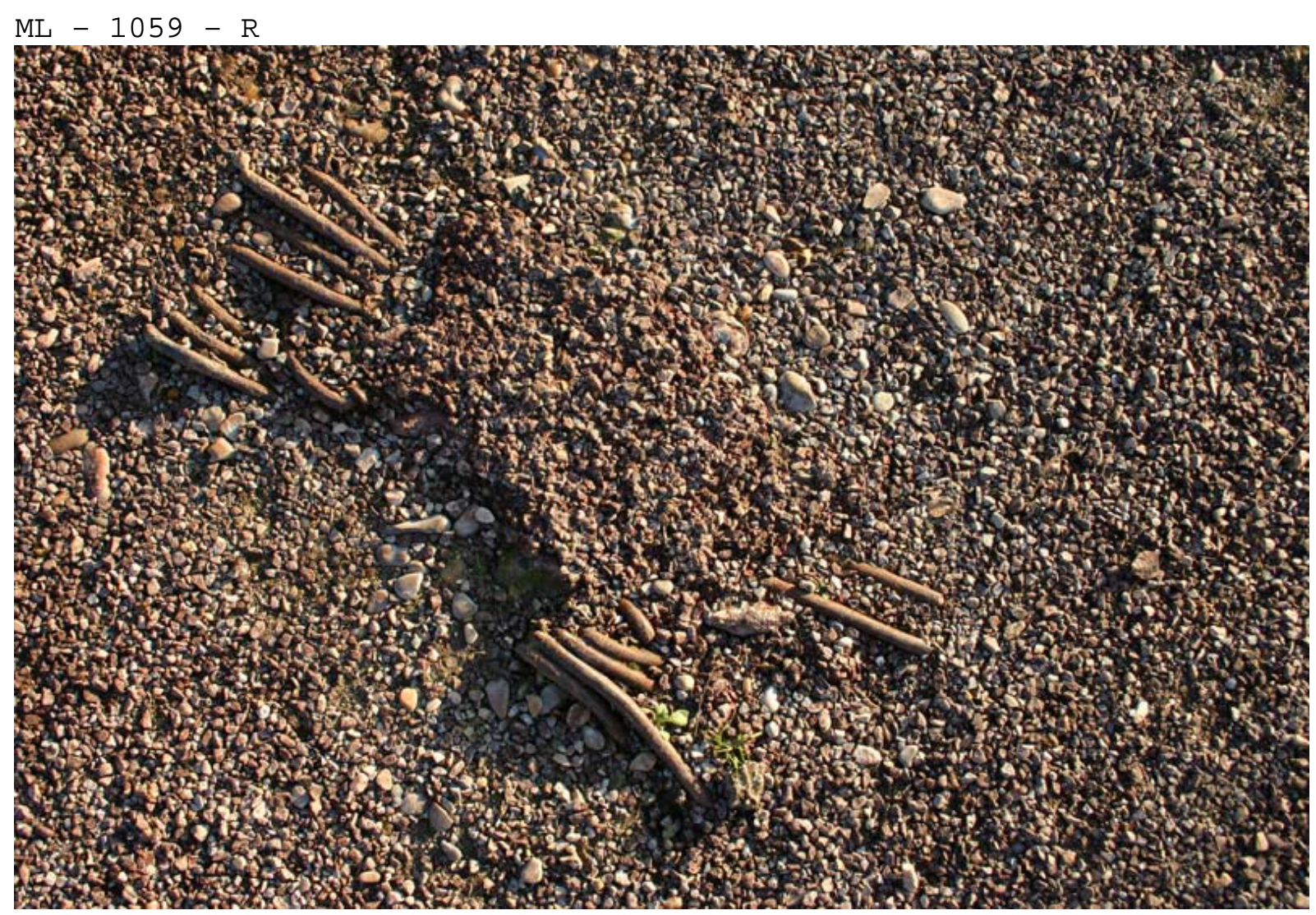

Myriapode bas-rhodanien faisant la sieste emberlificoté dans la digue de Caderousse (Vaucluse). Son rôle dans le biotope est sujet à conjectures. 


\section{$M L-488-R$}

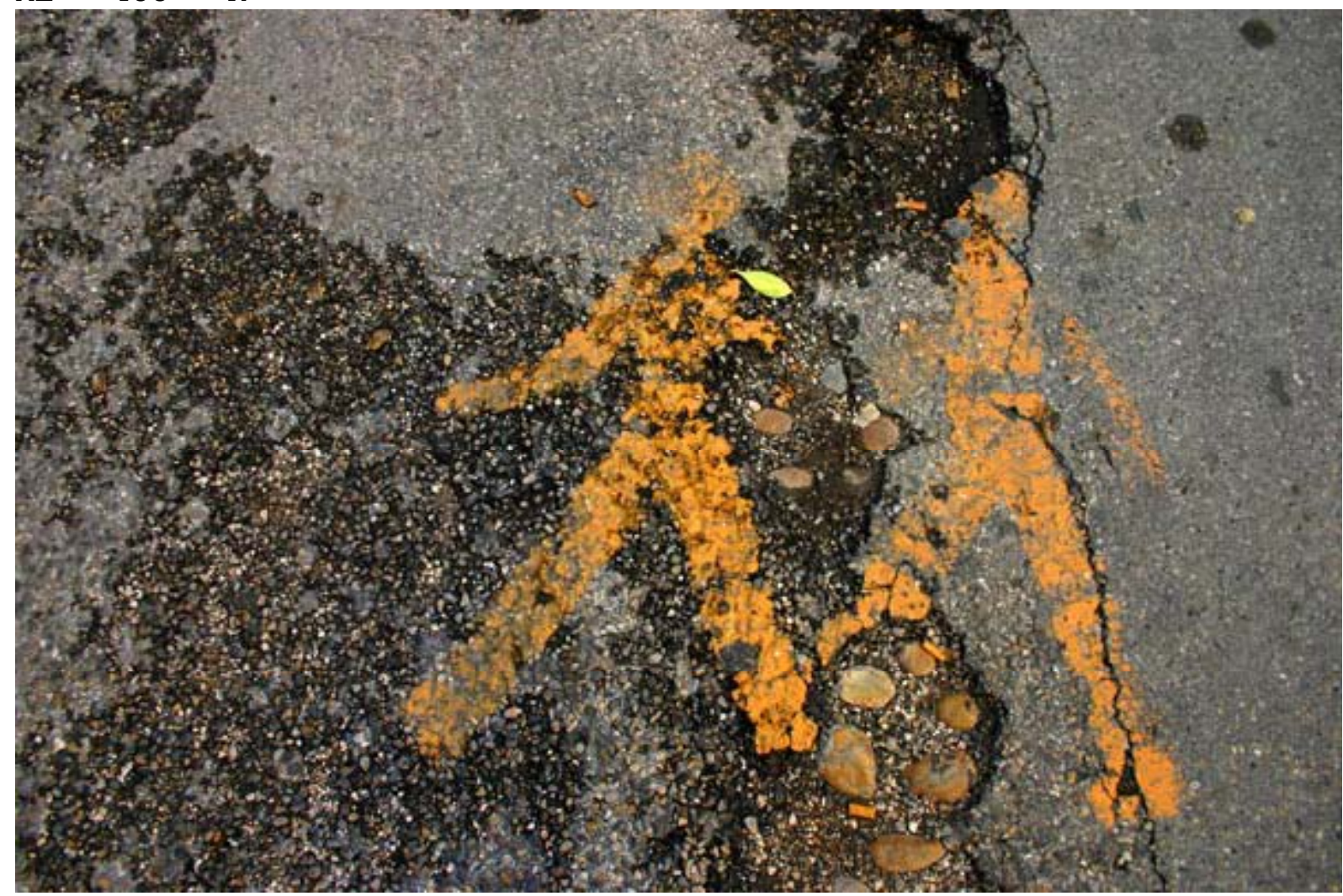

Deux Avenionais figés impromptu alors qu'ils se rendaient à un concert programmé par l'AJMI (Aujourd'hui Jouer de Manière Insolente).

On notera l'exceptionnel état de conservation de la cigarette de celui de droite. 


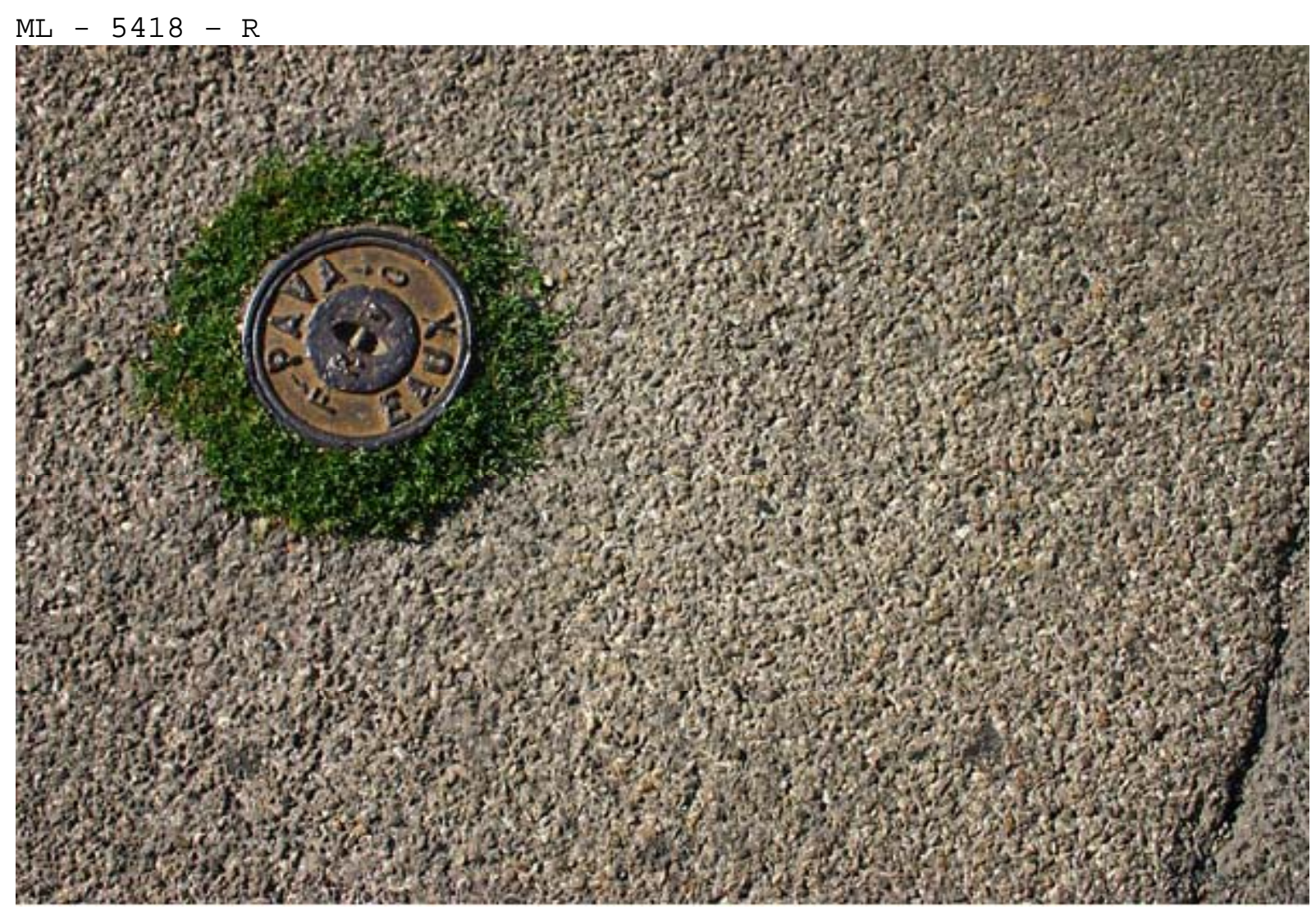

Illustre la stupéfiante capacité de la végétation locale à s'adapter à son environnement.

Ces herbettes ont été capables de déchiffrer la signalisation urbaine et de $s^{\prime}$ implanter à $l^{\prime}$ endroit exact où se trouve l'eau indispensable à leur survie. 
$M L-2077-R$

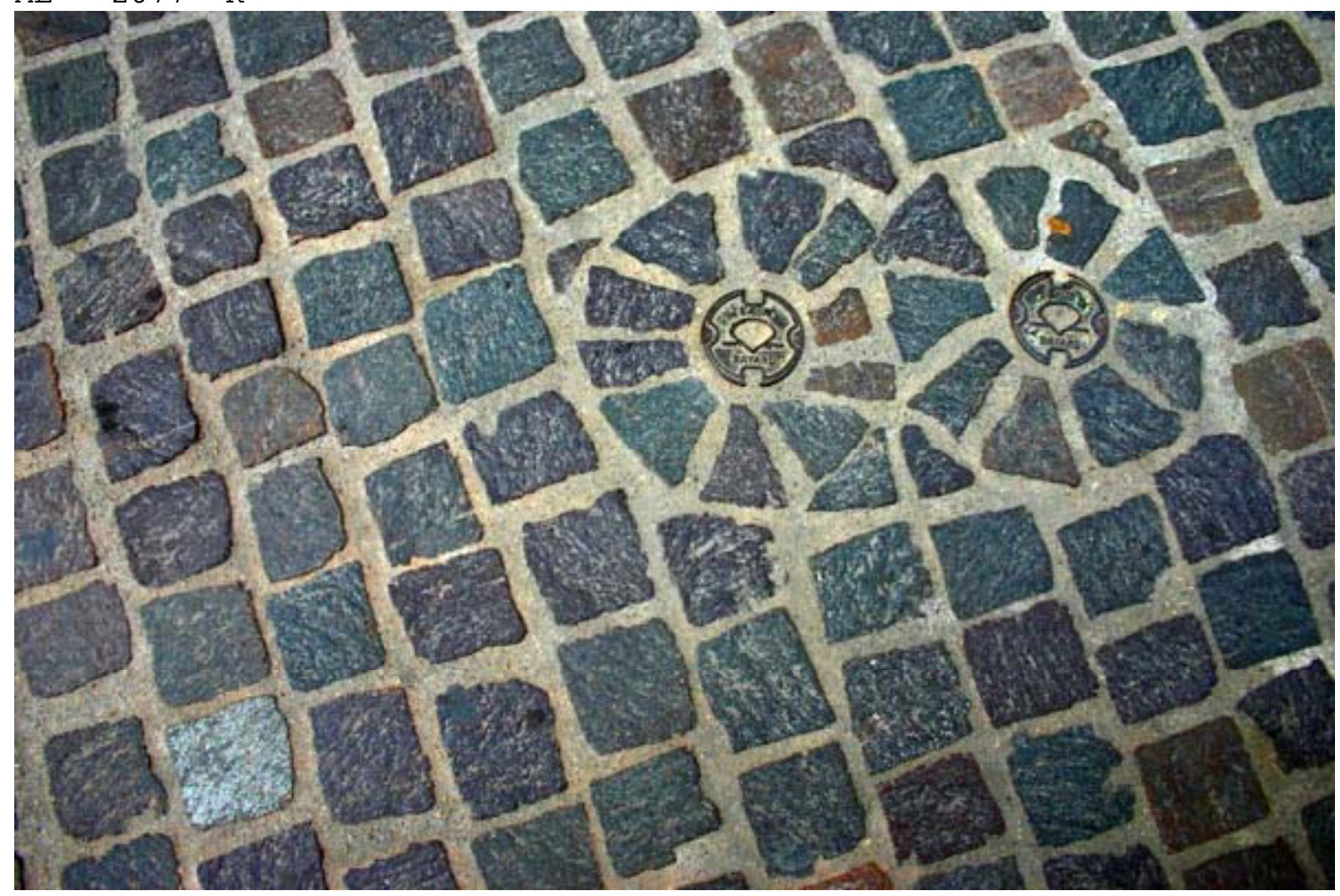

Exceptionnellement bien conservé, un bisou de pavés dans une future rue piétonne d'Avenio. 
$M L-2294-R$

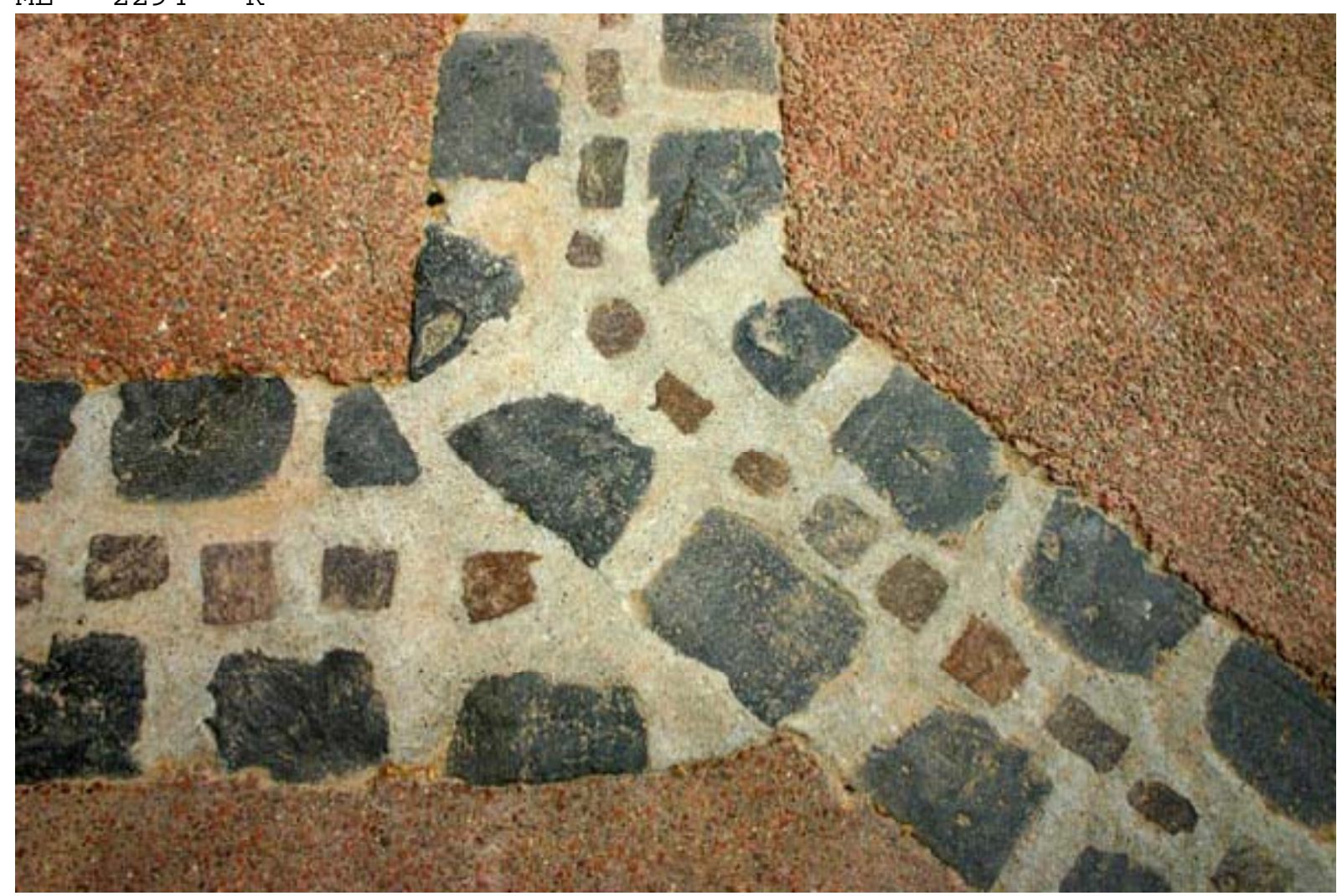

Dans une jungle urbaine référencée comme Lo Clapas, deux girafes se tiennent par le cou.

Dépôt Mélisande Barron, vendémiaire 214 


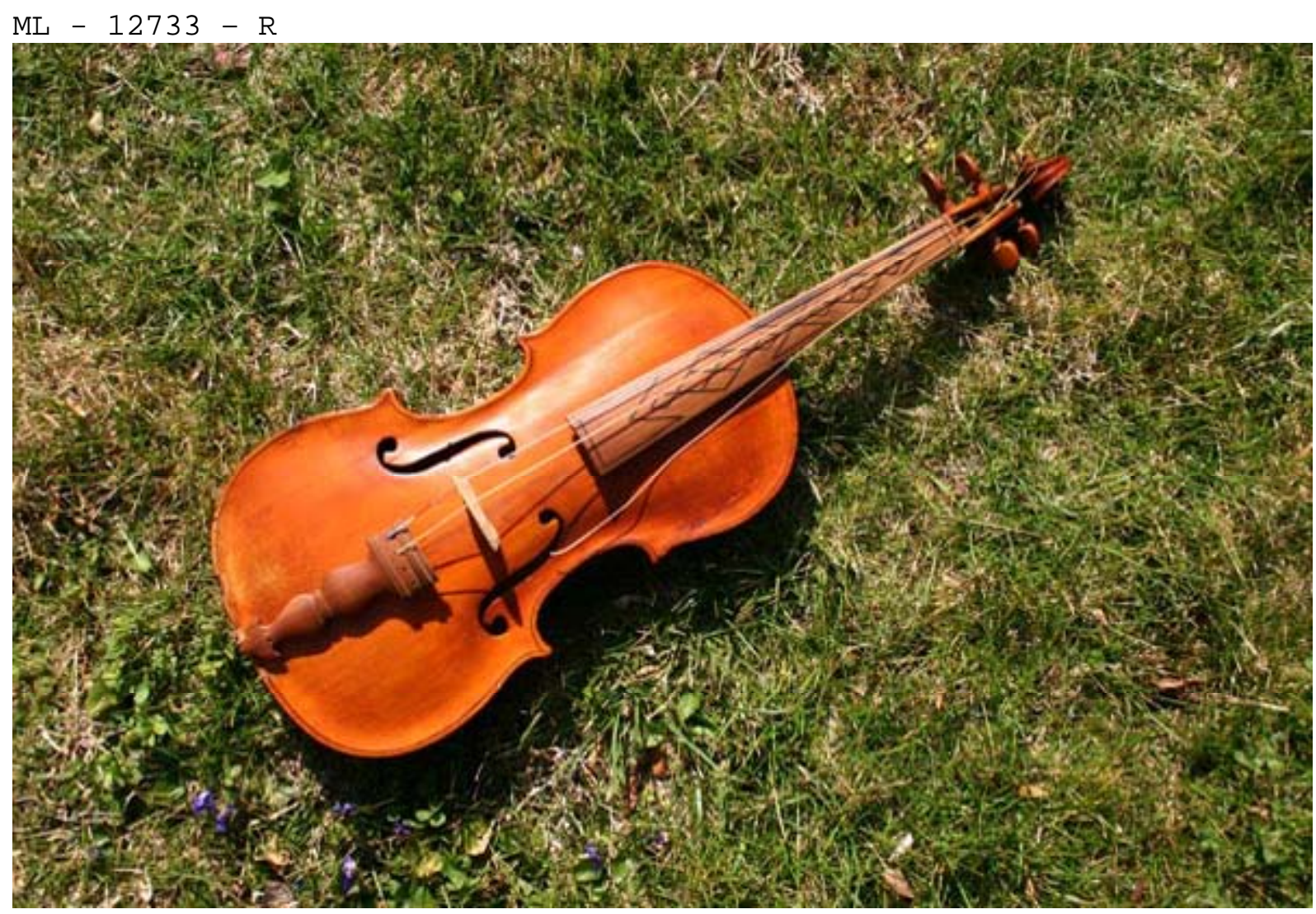

Violon utilisé par Perrin Tieques le 26 ventôse an 214, et grâce au son duquel il a mis en fuite un loup gris adulte affamé qui le poursuivait.

Le mélophobe est parvenu tout de même à arracher les cordes de ci, de là la et de mi.

L'instrument est conservé depuis ce jour dans la famille d'Inigo Cancapolin-Crémont, qui a bien voulu le mettre à la disposition de Gaile Mertas le temps de la photo. 
$M L-10878-R$

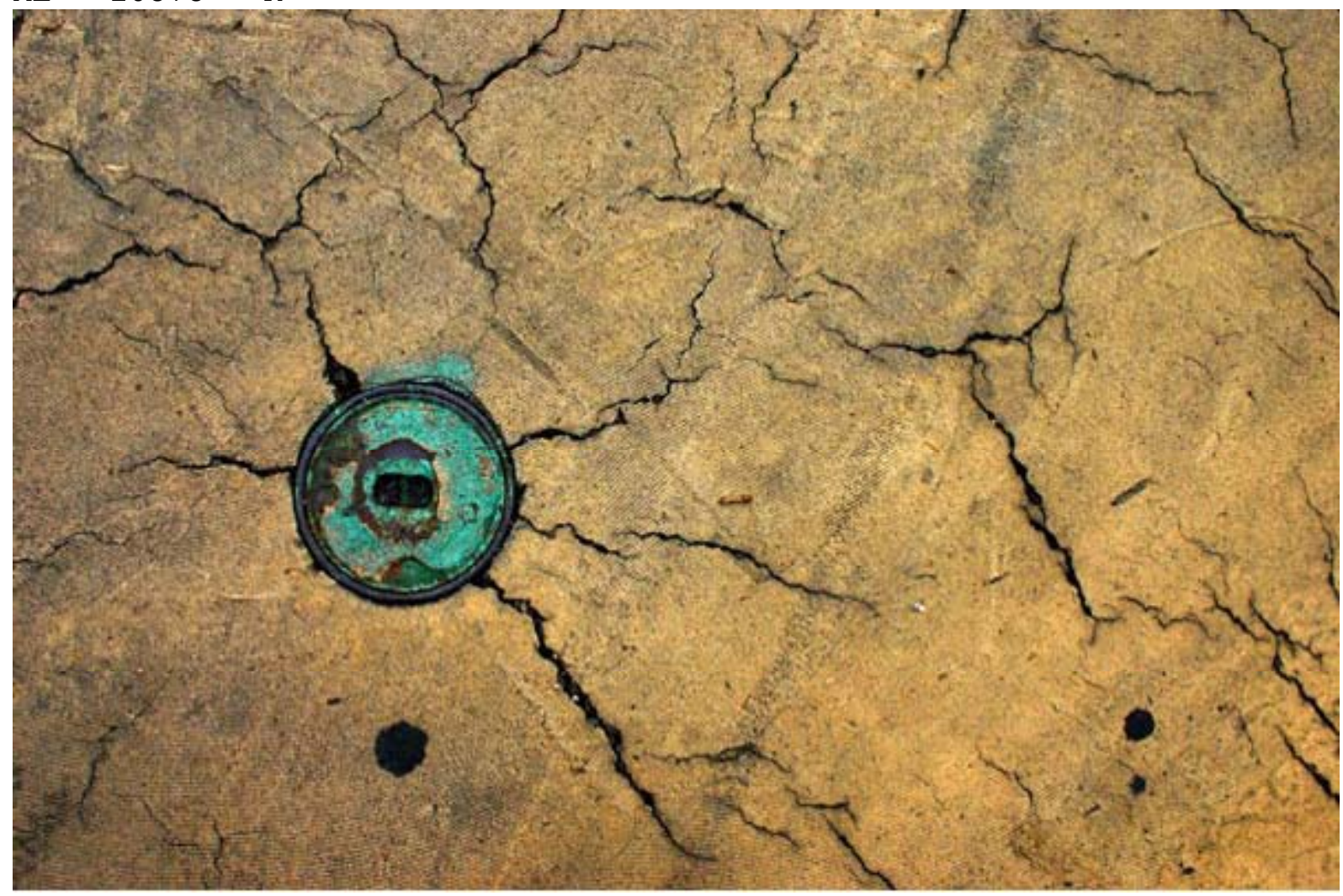

Emplacement pour ovni (Orteils Vernis Naturellement Instables) selon toute vraisemblance endommagé et désaffecté après plusieurs atterrissages violents. Était peut-être destiné aux élèves d'une ovni-école.

(reconstitution hypothétique) 


\section{$M L-7797-R$}

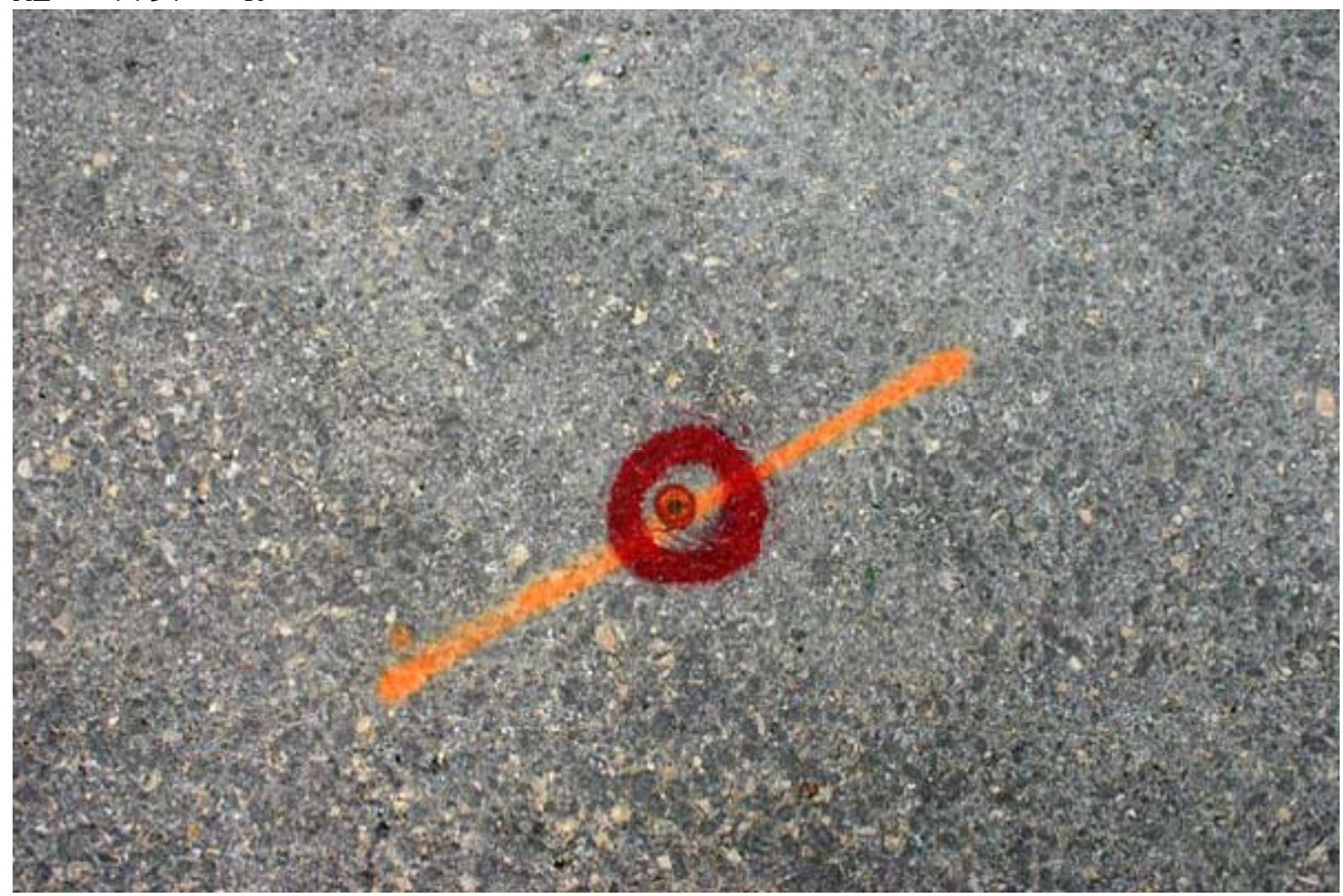

Emplacement d'atterrissage pour ovni (Ombres Vagues et Nuages Irisés).

Les savants pensent qu'il était spécialement destiné aux pilotes souffrant de malaises vagaux.

(reconstitution hypothétique) 
$M L-1728-R$

Avignon vu du rocher des Doms Le Rhône pris par les glaces, 4 nivôse 213

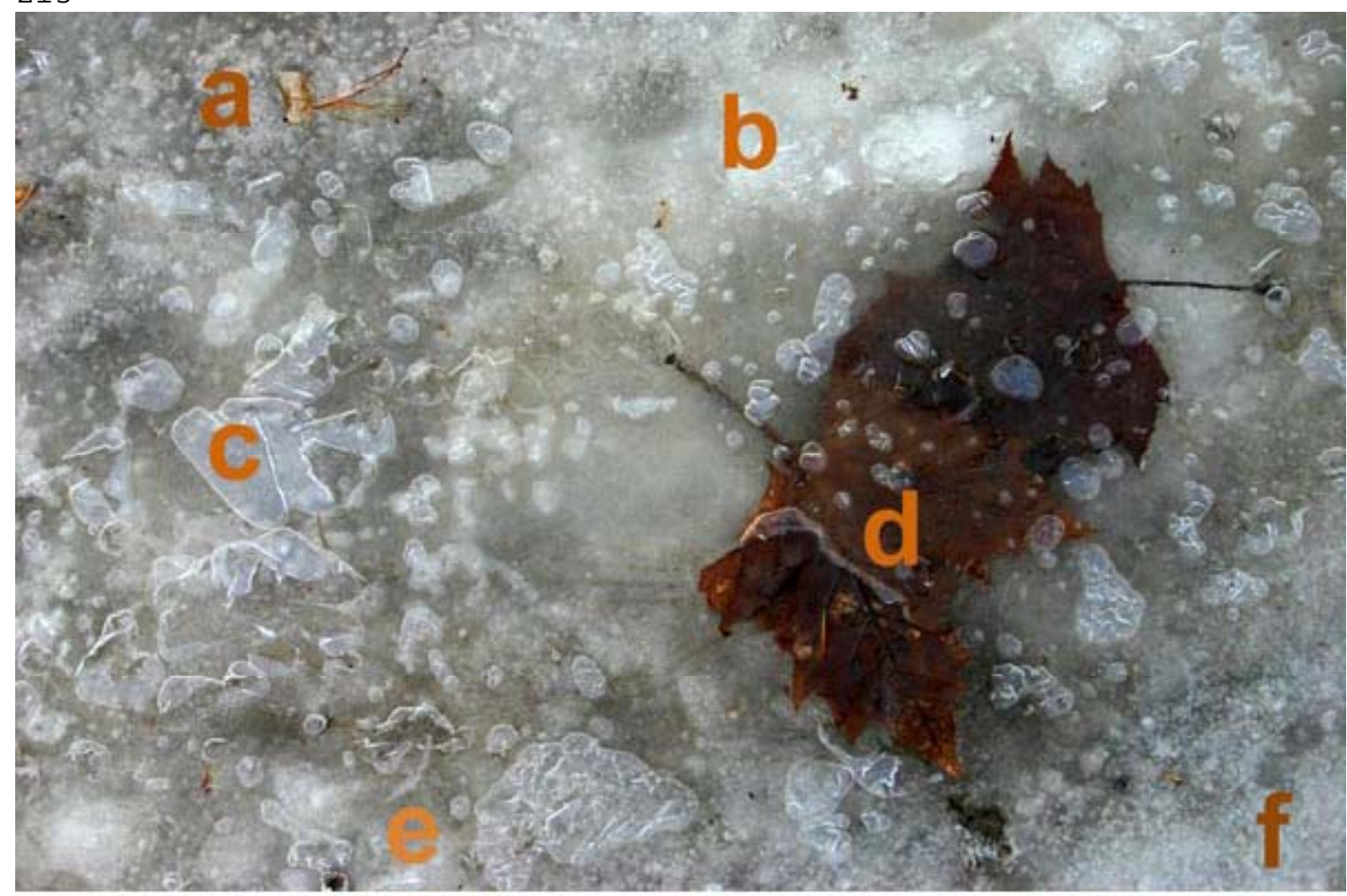

a ancêtre de poum-ploum box avec gps intégré

b Joseph vernet, attaché à un mât, étudie les effets de la tempête c message personnel

d allez, une citation: "J'appelle art l'expression de rapports inconnus et soudain convaincants entre les êtres, ou entre les êtres et les choses." Jean-Luc Godard

e une autre? d'accord! "L'art, c'est ce qui rend la vie plus intéressante que l'art" Robert Filliou

$f$ il y en aurait encore, mais la focale est trop courte 
$M L-11224-\mathrm{R}$

Avignon vu du rocher des Doms - circa xème siècle avant notre ère

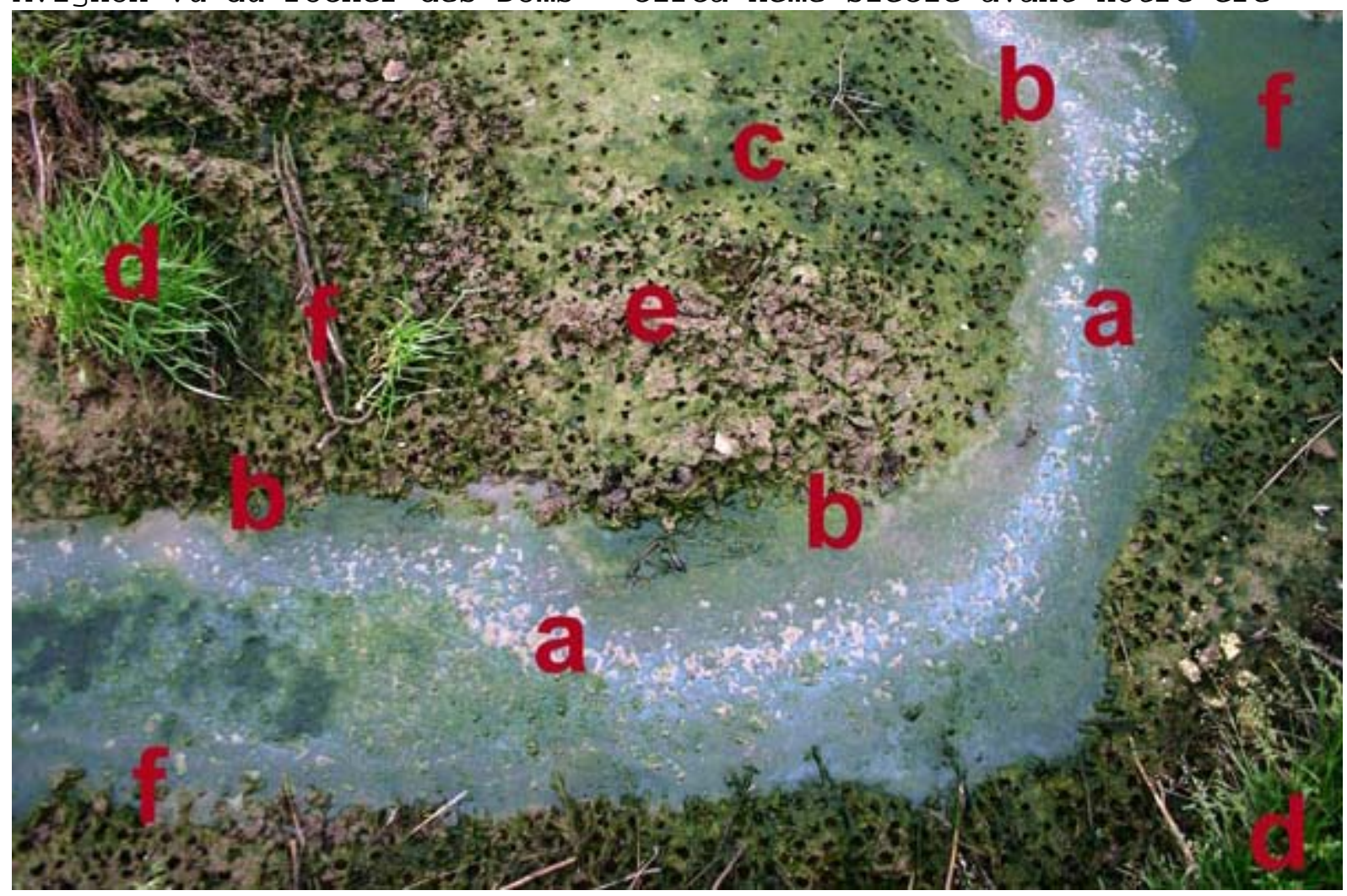
a le Rhône
b berges inondables
c marais
d bois: promenons-nous dans les -
e cheminées d'aération des résidences troglodytiques
$f$ etc 
ML- $2351-\mathrm{R}$

Avignon vu du rocher des Doms - Ère de la Bagnolite Triomphante années Sombres

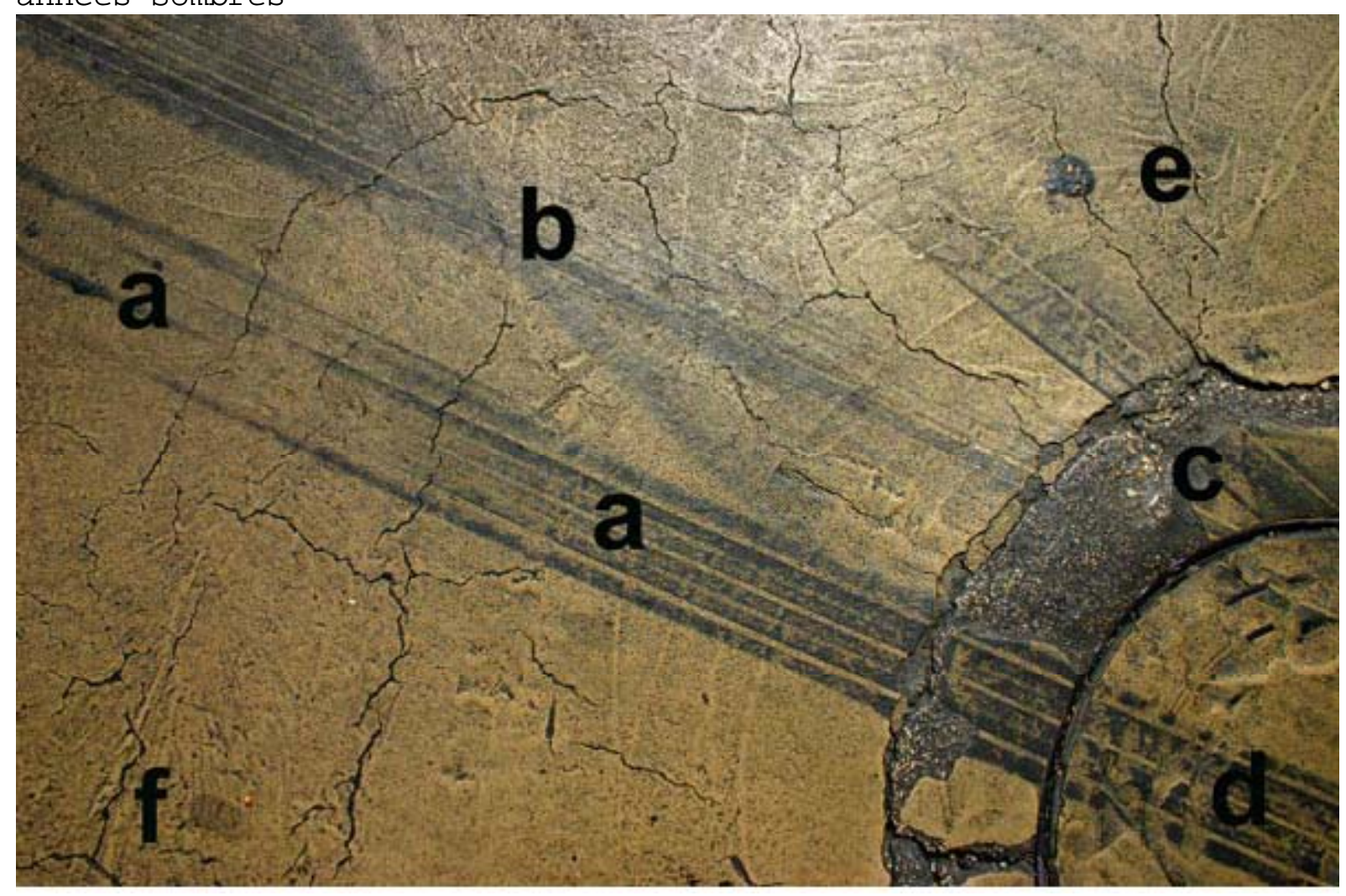
a itinéraire d'Avignon à Aix
b itinéraire Bison Fûté
c remparts délimitant l'intra muros
d rue portant le nom d'un massacreur de la Commune
e traces d'un accident de navette provençale à $l^{\prime}$ anis
$f$ signature du garagiste 
$M L-5928$ - R

plan de sécurité incendie

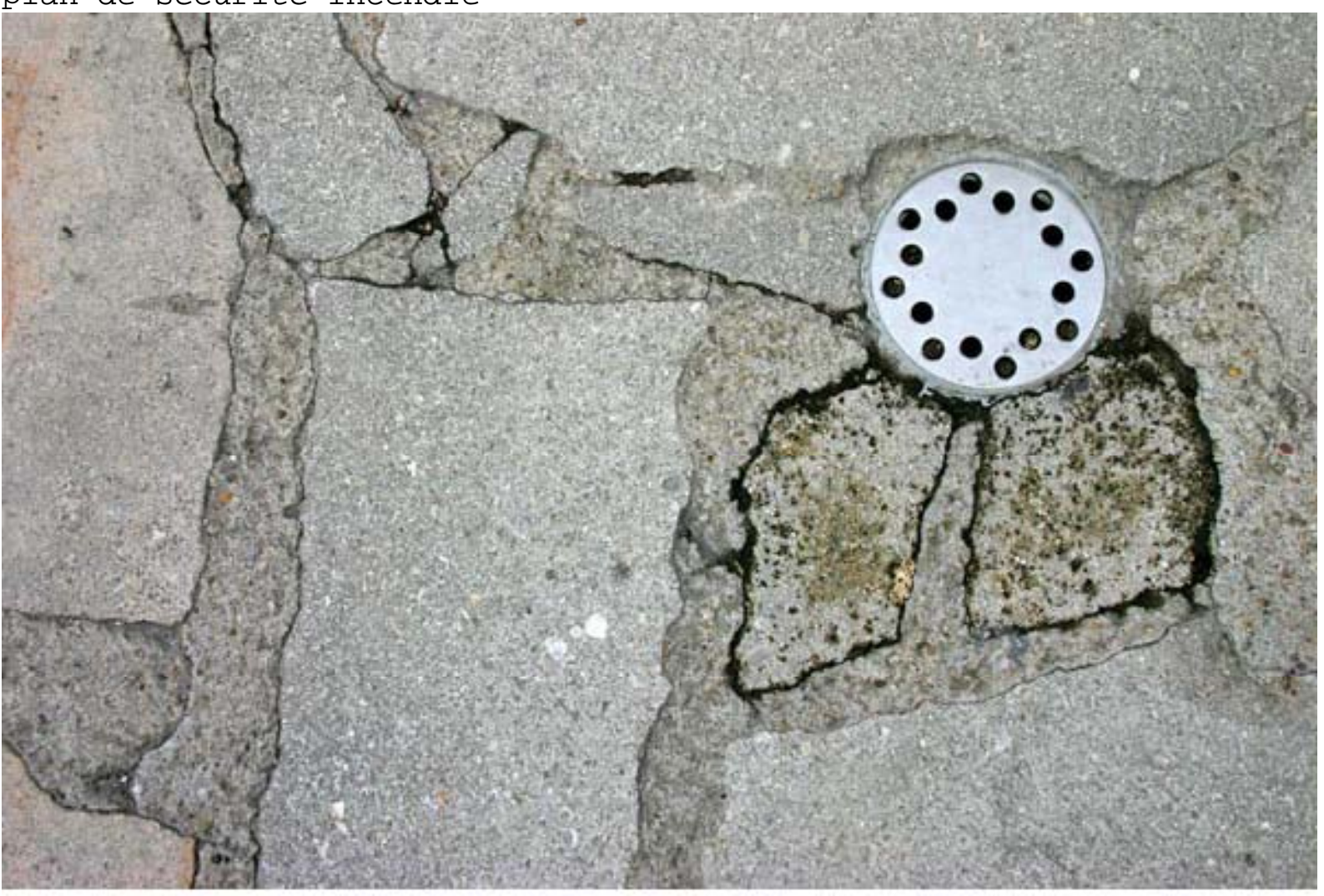
a extincteur
b coupure ventilation
c coupure force
d coupure lumière (années)
e sparadrap pour les coupures
$f$ commande désenfumage

(remarque presque illisible: aïe, on a oublié de repérer les légendes) 
$M L-15477-R$

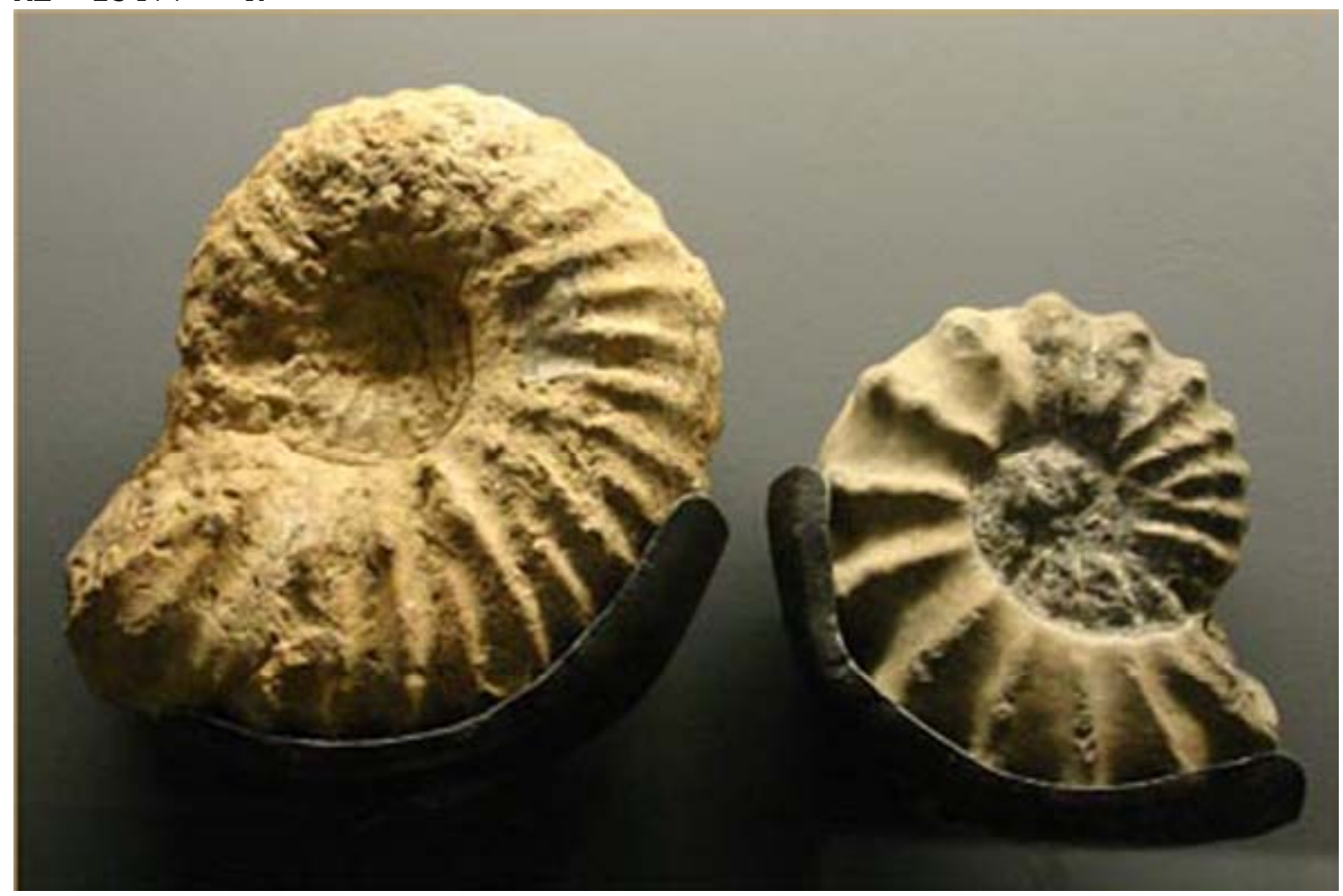

À VENDRE

STUDIOS TOUT CONFORT

950 et $540 \mathrm{~cm} 3$ habitables

dans hôtel particulier du XIXème $s$. avant notre ère.

Volumes atypiques. Architecture HQE.

Prévoir travaux.

AFFAIRE À SAISIR avec des pincettes

(note: les fossiles photographiés ci-dessus se trouvent dans une vitrine du Musée Requien; la photo et sa légende étaient disposées à côté de ceux-ci) 